\title{
Intergenerational replacement and migration in the countries and regions of the United Kingdom, 1971-2009
}

Chris Wilson and Lee Williamson

ESRC Centre for Population Change, School of Geography and Geosciences

University of St Andrews

\section{Abstract}

This article uses a recently proposed measure, the overall replacement ratio or ORR, to assess the extent to which migration alters intergenerational replacement within the United Kingdom. The UK as a whole can be seen to experience 'replacement migration' as immigration compensates for fertility below the replacement level. However, the article shows that the impact of migration differs radically in the different regions of the country. South East England experiences very substantial immigration from both the rest of the UK and overseas, far more than is needed for intergenerational replacement, whereas most of the rest of the UK sees little or no net immigration and the ORR remains below the replacement level. 


\section{Introduction and literature review}

Studies of intergenerational replacement have a long history within demographic analysis, and have taken on greater significance in recent decades as the UK, in common with almost all European countries, has experienced fertility below the level needed for replacement for a sustained period, in the case of the UK for almost 40 years. Conventional measures of replacement assess the combined effects of fertility and mortality, but many demographers now accept that the importance of migration for childbearing trends and population change in most developed countries implies the need to rethink the traditional concepts of replacement level fertility ${ }^{1}$.

However, in spite of the recognition that it is an important issue, no measure of replacement incorporating migration has yet become a de facto standard. Calot and Sardon ${ }^{2}$ suggested that 'net replacement rates' which reflect both mortality and migration are preferable to the widely used 'net reproduction rates' and that their inclusion may change the evaluation of future population prospects. This is well illustrated by Daguet ${ }^{3}$ who computed different measures of generational replacement for France. Taking a somewhat different approach, Preston and Wang ${ }^{4}$ have proposed an alternative method calculating the intrinsic growth rate and net reproduction rate in the presence of migration based on age-specific growth rates. Ortega and del Rey ${ }^{5}$ have proposed computing birth replacement ratios (BRE), relating period numbers of births to the mean size of the mothers' generation at birth. Del Rey Poveda and Cebran-Villar ${ }^{6}$ have used the BRE to illustrate the markedly different population dynamics of two Spanish regions in the twentieth century and have also provided a review of relevant methodological literature on replacement. Two further papers that have investigated the links between migration, fertility and population dynamics are Ediev et al. ${ }^{7}$ and Philipov and Schuster ${ }^{8}$. Dalla Zuanna ${ }^{9}$ has proposed an index of replacement including migration, RM, that is very similar to the measure used in this article, and has also used a similar approach to investigate differential regional replacement in Italy ${ }^{10}$. And, finally, Sobotka ${ }^{11}$ has proposed the gross replacement rate (GRE) that combines period estimates of fertility (the gross reproduction rate in the year of cohort's birth) with data on subsequent changes in cohort's population size to estimate replacement for each cohort.

Although all these measures have their strengths and weaknesses, in this article we prefer to use a recently proposed and very simple method to assess how far migration alters the extent of replacement for a birth cohort as it ages. In order to avoid all problems associated with the estimation of fertility, mortality and migration, we ignore the vital processes altogether, and just present a direct comparison of the size of age groups. The measure used here is the overall replacement ratio (ORR) proposed by Wilson et al. ${ }^{12}$. It is calculated by taking the size of a female birth cohort divided by the average size of the cohorts of mothers (or more exactly, potential mothers) in the year of birth. We use female cohorts to facilitate comparison with conventional fertility indices, but male cohorts (or the two sexes combined) could be equally well studied in this way. In its interpretation and aim, the ORR is very close to the gross replacement rate (GRE) proposed by Sobotka, and direct comparison of the two indices shows that we achieve almost identical results using the more simply defined ORR as the GRE. We prefer to use the ORR because it requires information solely on age structure, whereas the GRE uses the total fertility rate or gross reproduction rate as well as age structure. Although this is not a large advantage for contemporary national European populations, in some circumstances (for example for regional or 
local populations, or for sub-groups in the population, where age structure is known but agespecific fertility is not), the ORR could have significant advantages.

\section{Methods and data}

Our interest in this article is principally in the extent to which migration alters estimates of intergenerational replacement based solely on fertility and mortality in the context of belowreplacement fertility. Thus we focus on cohorts born in the 1970s and 1980s, when fertility in the United Kingdom fell below the replacement level for the first time since the 1930s. Given that the largest migration streams are usually those of young adults, we do not present results for later cohorts who have yet to reach the main migrating ages.

Following Wilson et al. ${ }^{12}$, we define the ORR as follows:

$$
\operatorname{ORR}(a, c)=F(a, t=c+a) /[F((m 1, m 2), t=c) / n]
$$

where $\mathrm{a}$ is age, $\mathrm{c}$ is the year of birth, $\mathrm{F}$ size of the female population, $\mathrm{t}$ the calendar year, $\mathrm{m} 1$ and $\mathrm{m} 2$ are the lower and upper bound of the age cohort of mothers, and $\mathrm{n}$ is the number of years contributing to the mothers' age range. In this article we take 20 and 35 (20-34 in completed years) for $\mathrm{m} 1$ and $\mathrm{m} 2$, as indicating the limits of the main childbearing ages during the 1970 s and 1980s, the birth cohorts which we are mostly studying here. The definition given here for data in single years of age can be readily extended to five-year age groups when needed.

For example, we can compare the size of a hypothetical 1980 cohort over time to the number of women in the main childbearing ages in 1980. Using annual estimates of the size of the 1980 cohort enables us to track the impact of migration on its implied level of replacement. In this hypothetical example the 1980 cohort of 300,000 aged 0 is produced by five million women aged $20-34$, an ORR of 0.9 . By age 25 the cohort has grown due to immigration to 350,000 , implying an ORR of 1.05 .

$$
\begin{aligned}
\operatorname{ORR}(0,1980) & =F(0,1980) /[F((20-34), 1980) / 15] \\
0.90 & =300,000 /[5,000,000 / 15] \\
\operatorname{ORR}(25,1980) & =F(25,2005) /[F((20-34), 1980) / 15] \\
1.05 & =350,000 /[5,000,000 / 15]
\end{aligned}
$$

Other age ranges and more complex definitions of the average size of the mothers' cohorts could, of course, be taken, but our initial analysis (see Appendix 1) suggests that for cohorts born in the United Kingdom in the 1970s and 1980s, 20-34 is the most suitable choice. In fact, the ORR does not seem to be significantly affected by the definition of the mothers' cohorts, as long as the range selected is large enough to wash out effects of short-term baby booms and busts. In historical populations and for more recent years (when fertility has been significantly delayed compared with the 1970s and 1980s), a broader age range (for example 20-44) might be more suitable. When calculating the ORR for populations in which there are significant perturbations in the age structure, more complex definitions of the mothers' cohorts may well be advisable. For present purposes, however, we have chosen to keep the definition as simple as possible. Because our 
main interest lies in tracking how the generation of mothers with below-replacement fertility is subsequently 'replaced', or not, by a positive migration balance, we focus on tracking the ORR until the ages at which their daughters typically become mothers themselves. At these ages, cohort survivorship in contemporary developed countries is practically unaffected by mortality, which makes the ORR changes over time almost entirely determined by fertility and migration. In the absence of migration, this ratio will remain almost constant for the first decades of life, and then decline as mortality reduces the size of the cohort. However, where there is significant net immigration, the ratio will rise as the cohort ages, with the increases taking place at the ages of immigration. Conversely, with net emigration, the ratio will decline as the cohort ages.

As is well known, most migrants are usually young adults; thus migration is a process that leads to additions or subtractions to the size of a birth cohort between roughly the ages of 15 and 40 . This age pattern of migration can strongly modify the size of each cohort before it reaches typical childbearing ages. For example, with extensive immigration it is possible for every cohort to reach the replacement level, while some widely used age structure indicators, such as the conventional age pyramid, show a striking shortfall in the relative size of the cohort throughout childhood.

A key assumption underlying the overall replacement ratio is that the age-pattern of fertility only needs to be taken account in a very elementary way, by indicating the upper and lower bounds of the main childbearing ages. The validity of this assumption can be examined by comparing the gross reproduction rate with the ORR. This is done in Appendix 1, where we conclude that the assumption is justified and that 20-34 represents the best age range for the cohorts of potential mothers.

In order to calculate the overall replacement ratio we simply need estimates of the population by age. Mid-year population estimates were downloaded from the websites of the Office for National Statistics (ONS), the General Register Office for Scotland (GROS) (now the National Records of Scotland, or NRS) and the Northern Ireland Statistical and Research Agency (NISRA), and in some cases made available to us via email by the members of those offices responsible for population estimates. It should be noted that population estimates are just that, estimates, not actual counts. However, it is clear that the various official agencies involved in making such estimates for the United Kingdom produce internally consistent and highly plausible sets of estimates, and that these provide the basis for a detailed understanding of population dynamics in the United Kingdom.

\section{Results}

The results of our analysis are presented in Figures 1 and 2. Figure 1 shows the ORR by single years of age for cohorts born between 1972 and 1986 (in alternate years) in England and Wales, Scotland and Northern Ireland, while Figure 2 shows the ORR for Wales and the English regions in five-year age groups at five year intervals. The graphs enable us to see how the initial value of the ORR for each cohort, determined by fertility, is modified by migration (both internal and international) as the members of the cohort age. Given the definition of the ORR, the 1.0 line is a convenient indicator of the replacement level.

It is immediately clear from Figure 1 that the three countries have experienced substantially different demographic regimes over the last four decades. England and Wales presents the 
simplest pattern. For most cohorts the initial ORR value declines slightly over the first ten or so years of life; this is the result of net emigration by families, with young adult emigrants taking their children with them. However, the outflow is modest for all cohorts and scarcely evident for some.

\section{Figure 1 Overall Replacement Ratio (ORR) for England and Wales, Scotland and Northern Ireland, cohorts born 1972-1986, ages 0 to 35}
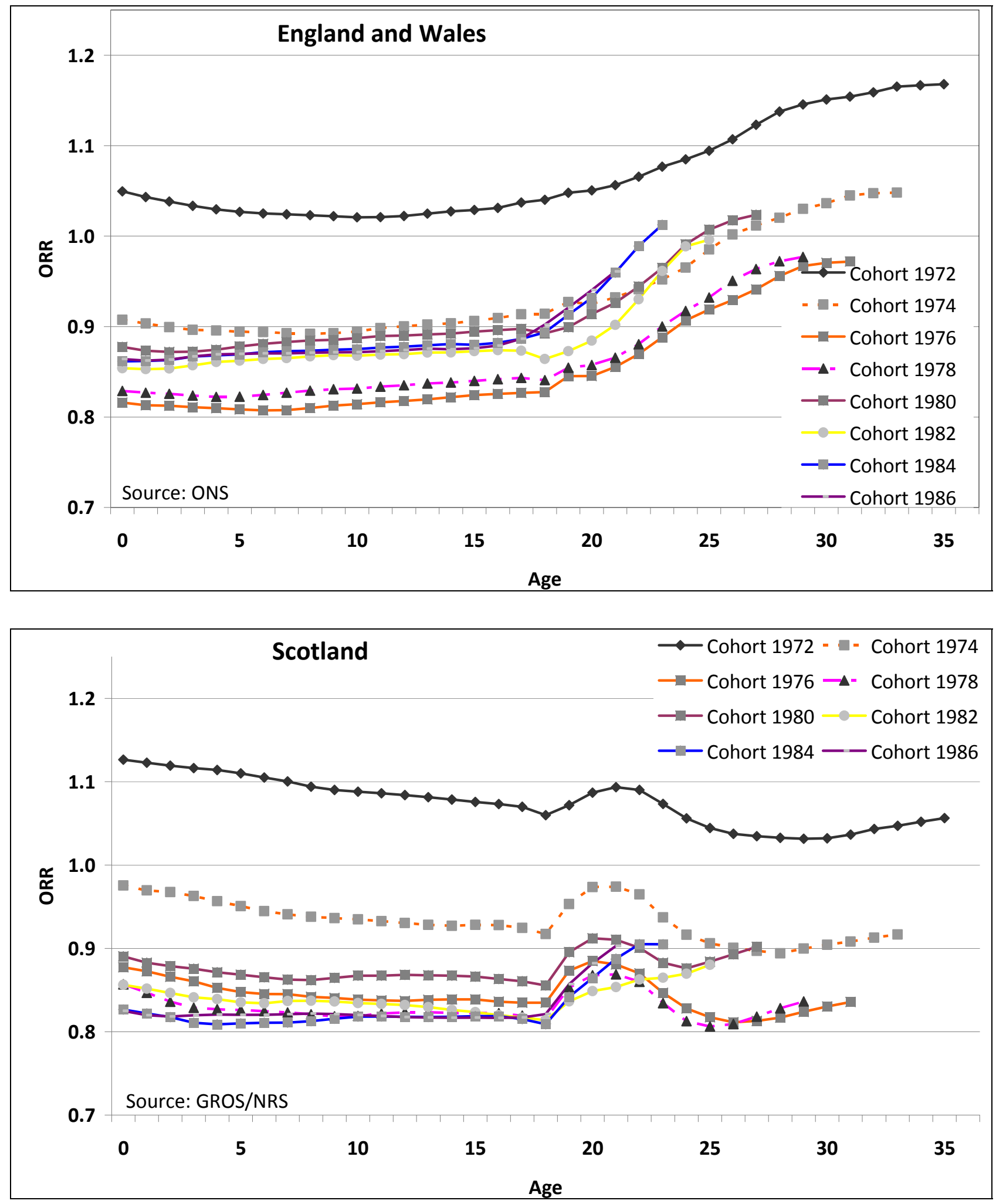


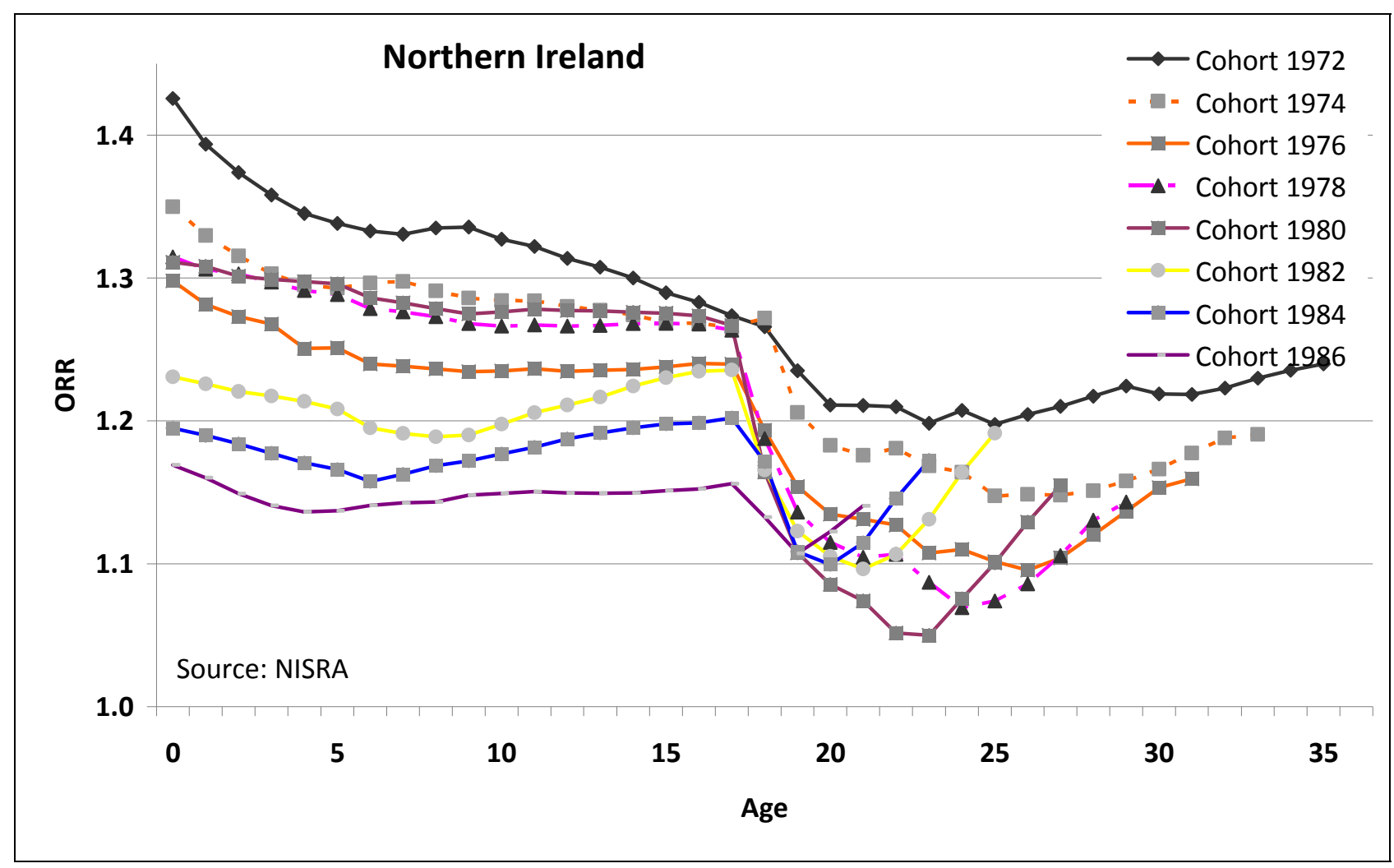

From the late teens on, there is a marked change as net immigration begins to increase substantially the size of each cohort. Between the late teens and age thirty the ORR for cohorts born in the 1970s rises, indicating that the cohorts have grown roughly 10-15 per cent. Most of this increase for England and Wales is due to net international immigration. Moreover, the pattern seen for England and Wales seems to be remarkably stable over time, and is similar to national estimates for most of Western Europe. Although fertility has been below replacement since the early 1970s in much of Western Europe, overall replacement is close to or above one ${ }^{12}$. In short, the demographic regime of England and Wales can reasonably be described as an example of 'replacement migration'.

The pattern of the Scottish ORR graph is strikingly different. Fertility initially was somewhat higher in Scotland than in England and Wales, as had been true for many decades, but the ORR values for most cohorts fall steadily from age 0 to the mid-teens; this is an indication of the scale of net emigration from Scotland, principally to England. For most of the 20th century Scotland had positive natural increase, sometimes very positive (for example during the 'baby boom' of the 1950 s and 1960s), but the population scarcely increased from around 1920 to 2000 , and fell in some years. The surplus of births over deaths was, for practical purposes, all exported, with the largest movement being to England. Towards the right hand side of the Scottish panel, however, we see a different story. Between 18 and 22 there is a significant upward bulge in all the ORR lines, indicating the extent to which Scotland attracts students in higher education. For most cohorts the gain during the ages 18-22 is lost afterwards, but in recent years the loss is modest and all cohorts show an upward turn at the extreme right of the figure. This indicates the net immigration (both international and from the rest of the UK) that Scotland has seen since 2002. During the last decade Scotland has become a net receiver of migrants, something not seen in the 
20th century. However, the inflow has not yet reached the extent needed to enable any of the cohorts born with ORR values below 1.0 to breach that line and achieve replacement.

The panel for Northern Ireland shows a more extreme version of the Scottish model of high fertility and large scale emigration, though with the difference of a net outflow during the years of higher education. The initial ORR values for Northern Ireland are much higher than elsewhere in the UK, since fertility there did not fall to the replacement level until much later, thus the scale for this graph differs from the two other panels in Figure 1. In spite of very large net outflows, and a marked exodus during the years of higher education, no cohort falls as low as 1.0 at any age, and there is evidence of net inflow among those in their early twenties.

Figure 2 decomposes England and Wales into its constituent regions, enabling us to examine the differing patterns of overall replacement seen around the country. The regional panels are arranged in a roughly north-south manner, and are presented in the form of five-year age groups at intervals of five years. There are two reasons for preferring five-year age groups. Firstly, singleyear population estimates are not available for the regions until 1991, so the graphs would be incomplete, and secondly many of the regions show very marked changes in cohort size during the main years of tertiary education, and the attendant bulges and troughs in the curves tend to dominate the picture, making broader interpretation more difficult. For simplicity four cohorts are presented: 1976, 1981, 1986 and 1991, the initial value is thus cohorts born in the five years preceding each date.

\section{Figure 2 Overall Replacement Ratio (ORR), Regions of England and Wales, and United Kingdom minus South-East England}

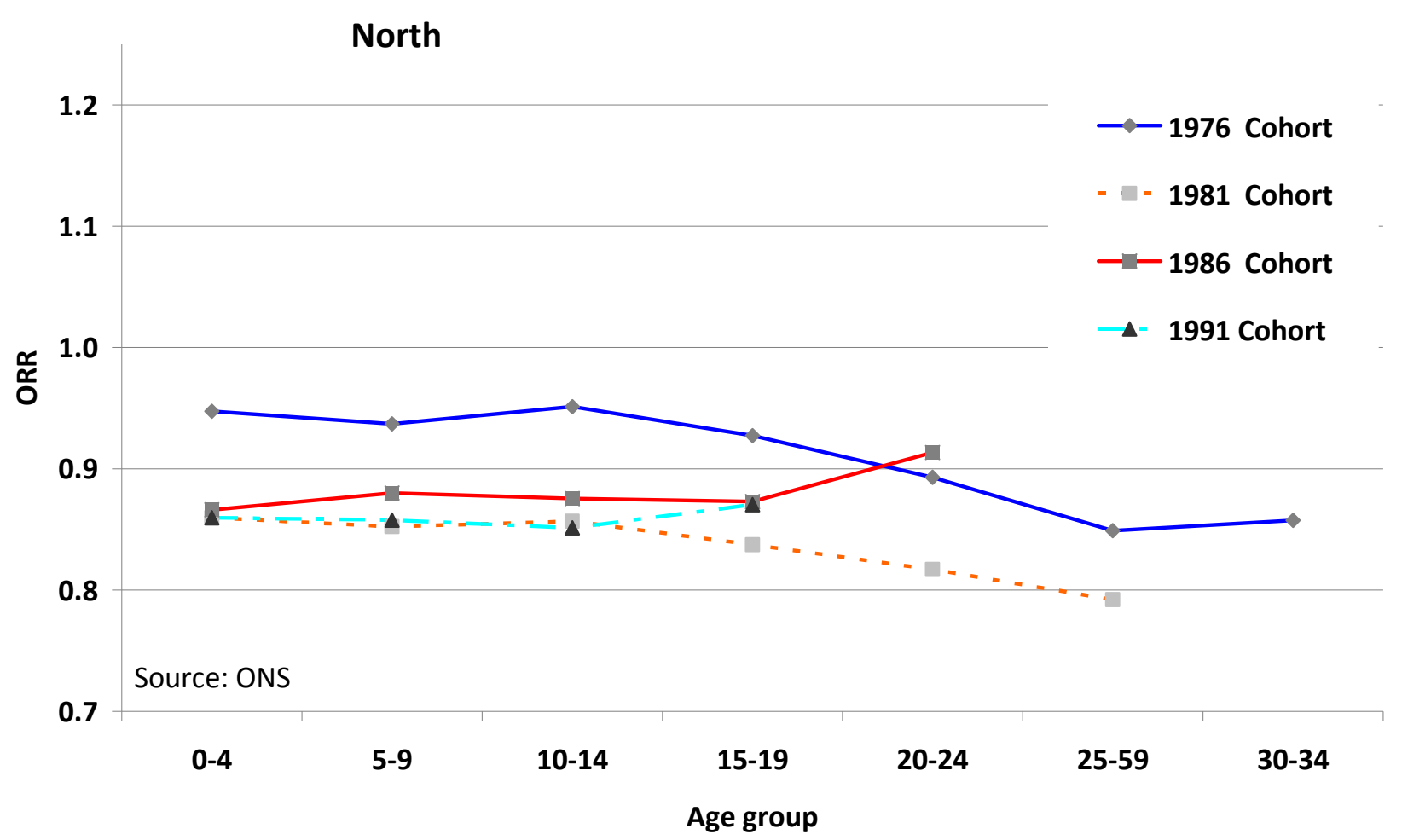



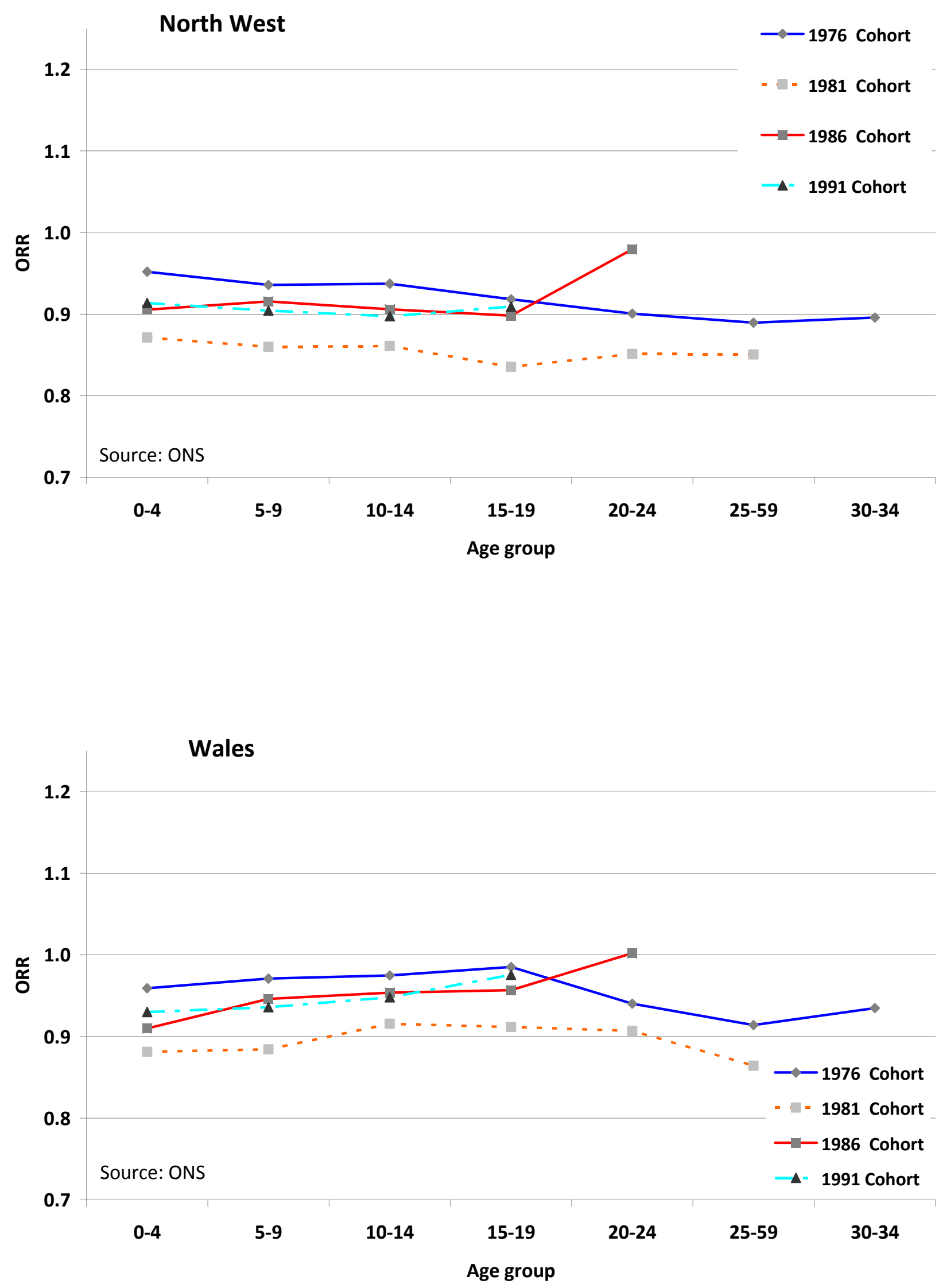

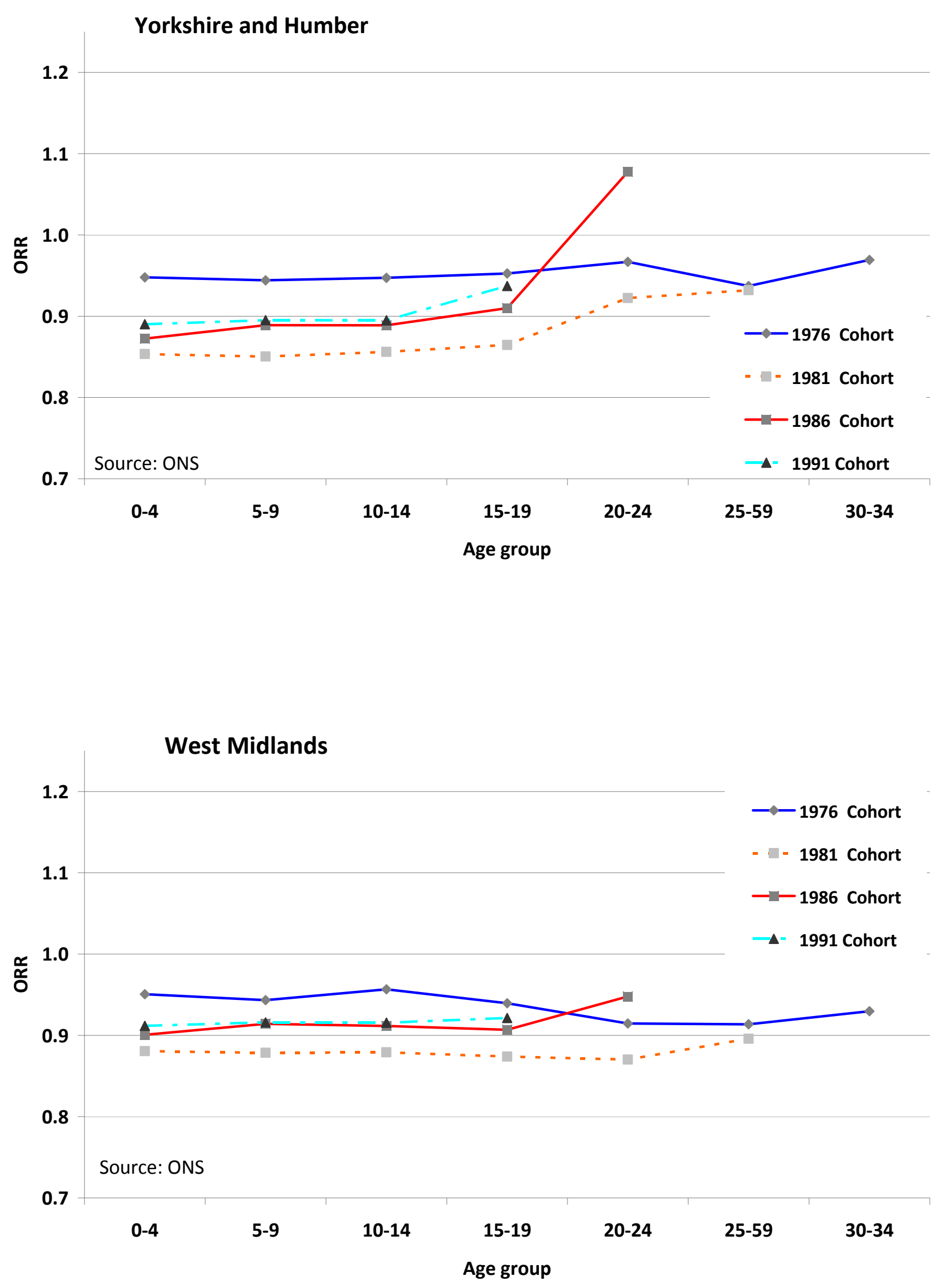

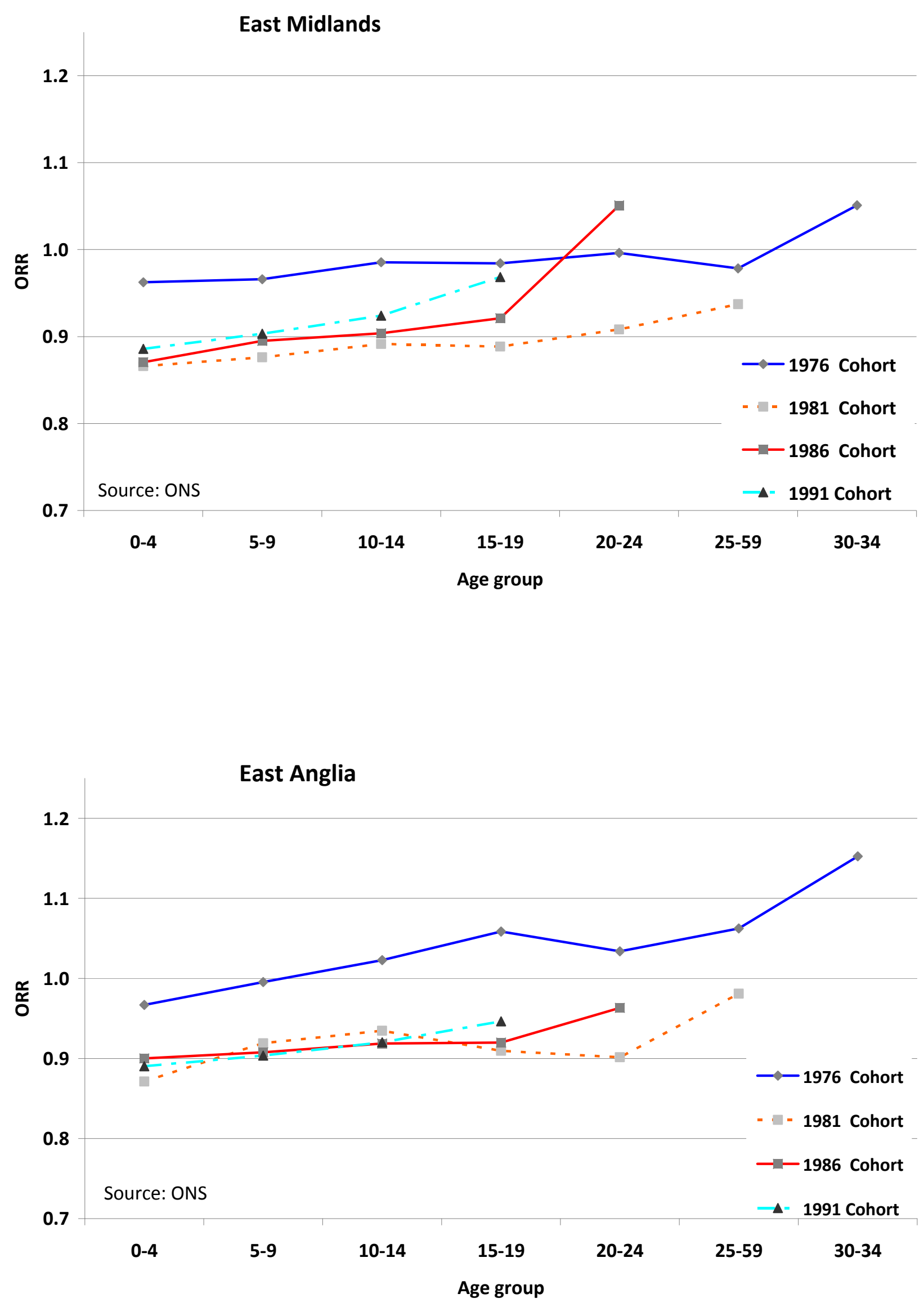

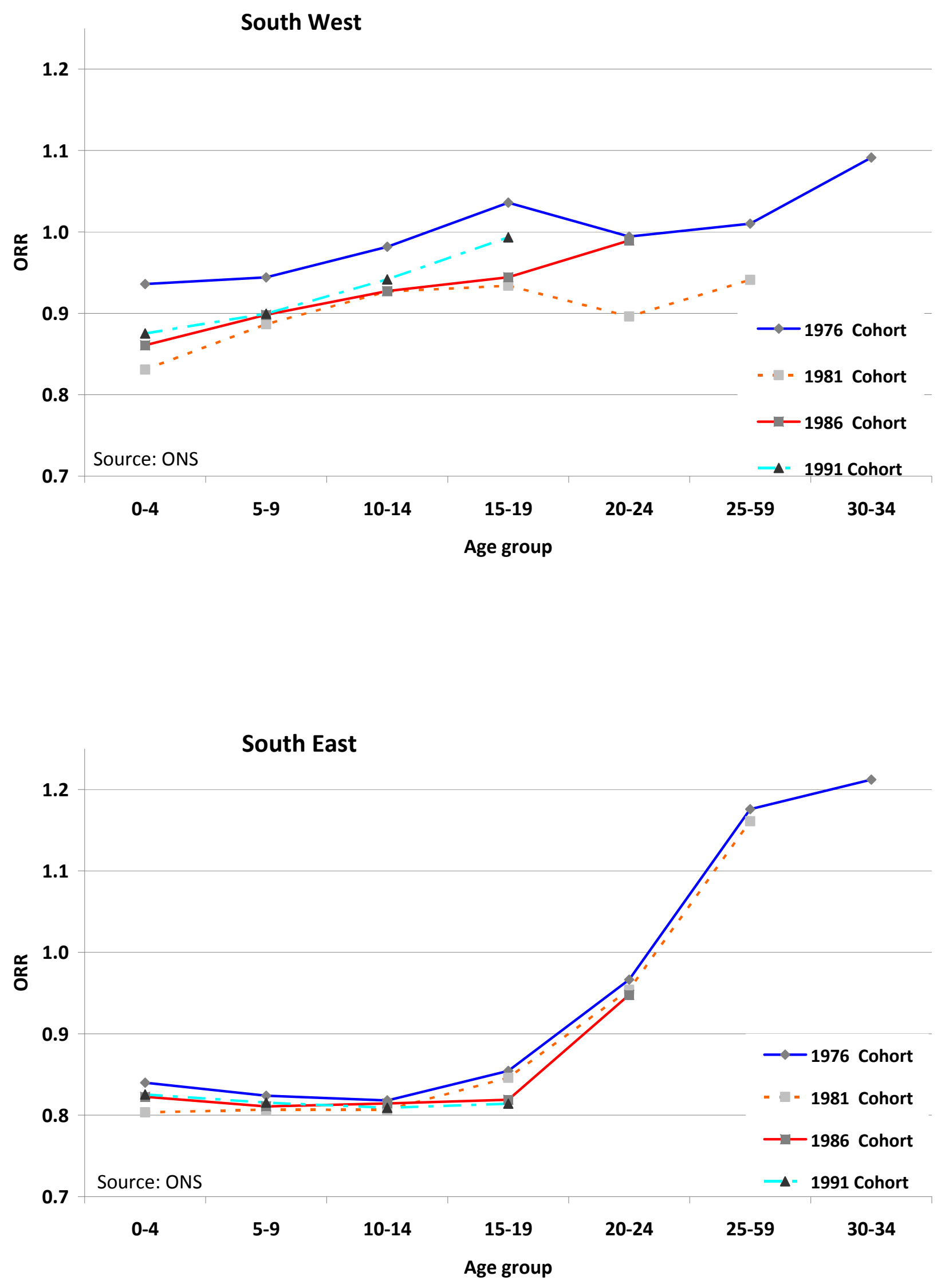


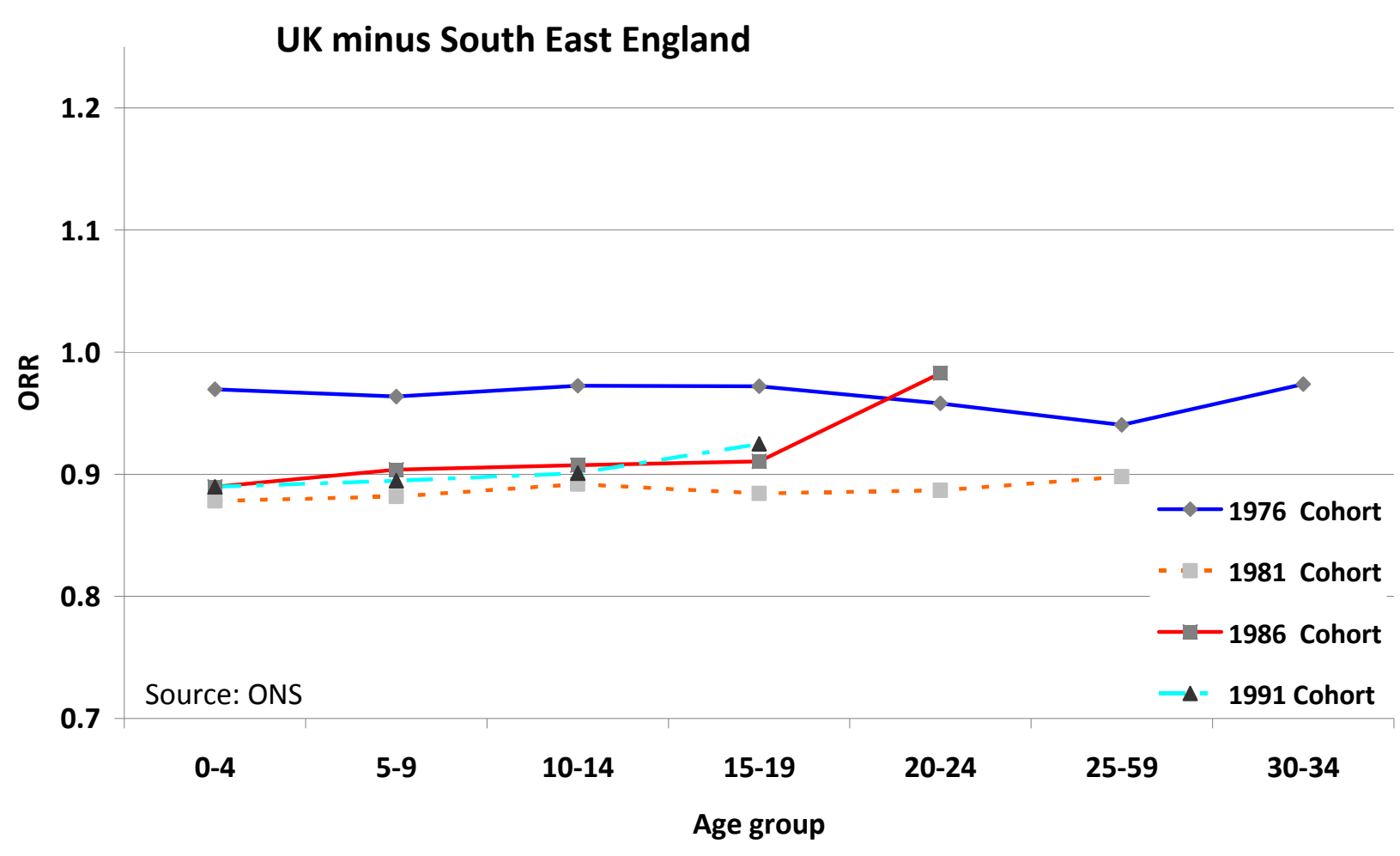

Many of the first panels in Figure 2 show remarkably stable ORR values, with little change as each cohort ages. The ORR values for the northern regions (North, North-West and Yorkshire and the Humber), the West Midlands and Wales are all broadly horizontal and struggle to pass the replacement level at any age. In these regions net migration is close to zero and there is no sign of replacement migration. In contrast, some cohorts in the East Midlands, East Anglia and South West regions pass the 1.0 line, showing that immigration is cancelling out the effect of below replacement fertility. However, by far the most striking graph is that for South East England, where from the late teens on the ORR rises sharply for all cohorts, and far exceeds the replacement level by the late twenties. The scale of increase is substantial by any standards, for example the 1976 and 1981 cohorts both increased their numbers by over 43 per cent between the ages 10-14 and 25-29. The scale of migration into South East England, both from elsewhere in the UK and overseas, clearly goes well beyond anything that could be called replacement migration. To provide a contrast with the graph for the South East, the final panel in Figure 2 shows the ORR for the United Kingdom minus the South East. The contrast could scarcely be clearer; once the South East is removed the UK does not experience replacement migration.

\section{Conclusions}

This article has used the ORR to examine trends in intergenerational replacement in the United Kingdom. We feel that the exercise has both demonstrated the utility of the ORR as a convenient indicator of replacement and highlighted the very different impact of migration in the regions and countries of the UK.

Our first conclusion is methodological. The ORR is a simple, even crude, index, but its simplicity is in fact its strength. It is easy to compute, has minimal data requirements, can be compared over time and across countries and regions, and is intuitively understandable. Appendix 1 , which 
compares the ORR at age 0 with the gross reproduction rate for England and Wales, suggests that the ORR may make a reasonable proxy for the conventional index when detailed information on fertility is lacking. The overall replacement ratio does not aim to substitute for any of the existing and more sophisticated measures of population dynamics, but we think it can play a useful role as a simple measure for indicating the combined effects of fertility and migration on intergenerational replacement.

The main substantive conclusion to emerge from this article is also clear: when considering the impact of migration on intergenerational replacement, we must distinguish South East England from the rest of the United Kingdom. Roughly one third of the UK's population live in South East England, yet this region absorbs the lion's share of net immigration for the whole country. Only in a few other regions of England (East Anglia, the East Midlands and the South West) and in Northern Ireland (where fertility was high in the 1970s and 1980s) does the ORR exceed 1.0 by age 30, indicating that replacement has been achieved. In this context, it is scarcely surprising that attitudes towards immigration (both among policy makers and the general public) can differ radically around the United Kingdom.

\section{Acknowledgements}

Much of the data used in this article was generally available online. However, several people helped us to locate specific tabulations. In this context we wish to thank the following people: at ONS, Becky Eddolls, Matthew Ford, Tony Hitching and Sue Reeves; at GROS (now NRS), Eileen Crichton. We also wish to acknowledge helpful comments from Tomáš Sobotka during the preparation of the article. All interpretation and conclusions are the responsibility of the authors.

\section{References}

1 Smallwood S and Chamberlain J (2005) 'Replacement fertility, what has it been and what does it mean?' Population Trends 119 (Spring 2005) 16-27.

2 Calot, G and Sardon, J-P (2001) ‘Fécondité, reproduction et remplacement’ Population 56(3) 337-396

3 Daguet, F (2002) 'Le remplacement des générations.' Chapter 12 in Un siècle de fécondité française: caractéristiques et evolution de la fécondité de 1901 á 1999. Paris: INSEE: 235-252.

4 Preston, SH and Wang, H (2008) 'Intrinsic growth rates and net reproduction rates in the presence of migration' Population and Development Review, 33(4) 657-666.

5 Ortega, JA and del Rey Poveda, A ( 2007) 'Birth replacement ratios in Europe: a new look at period replacement.' Paper presented at the 2007 Annual Meeting of the Population Association of America, New York, 29-31 March 2007

6 del Rey Poveda, A and Cebrán-Villar, M (2010) 'Population replacement and migration in two Spanish regions during the twentieth century' Population-E 65(3) 481-497. 
7 Ediev, D, Dalkhat, Coleman, D and Scherbov, S (2007) 'Migration as a factor of population reproduction'. Vienna Institute of Demography, European Demographic Research Papers, 2007(1). Available at: www.oeaw.ac.at/vid/download/edrp_1_07.pdf

8 Philipov, D and Schuster, J (2010) 'Effect of migration on population size and age composition in Europe'. Vienna Institute of Demography, European Demographic Research Papers, Available at: www.oeaw.ac.at/vid/download/edrp 2 10.pdf

9 Dalla Zuanna, G (2008) 'La misura RM del rimpiazo delle generazioni', Populazione e Storia 2008 (2) 61-72

10 Dalla Zuanna, G (2006) 'Population replacement, social mobility and development in Italy in the twentieth century'.Journal of Modern Italian Studies 11 (2) 188-208.

11 Sobotka, T (2008) 'Does persistent low fertility threaten the future of European populations?' in Deboosere, P, Surkyn, J and van Bavel, J (eds.) Demographic Challenges for the 21st Century. A State of the Art in Demography. Liber Amicorum Ron Lesthaeghe. Brussels: VUB Press: 27-89.

12 Wilson, C, Sobotka, T, Williamson, L and Boyle, P (2010) 'A simple method for estimating intergenerational replacement based on fertility and migration - European examples'. ESRC Centre for Population Change, Working Paper 10. Available online at: www.cpc.ac.uk/publications/ 


\section{Appendix 1}

\section{Comparing the overall replacement ratio and the gross reproduction rate}

A key assumption underlying the overall replacement ratio is that the age-pattern of fertility only needs to be taken account of in a very elementary way, by indicating the upper and lower bounds of the main childbearing ages. The validity of this assumption can be examined by comparing the gross reproduction rate (GRR) with the ORR.

Figure A1 presents the GRR and the ORR(age 0) defined in three different ways for England and Wales from 1971 to 2002, while Figure A2 shows the percentage deviation from the GRR for each of the three definitions of the ORR. It is clear that the suitability of the three definitions of potential mothers' cohorts (20-34, 20-39 and 20-44) varies over time. However, at every point the best fitting ORR(birth) comes very close to the GRR. In fact, over the whole 32-year span the best fitting value is never as much as two per cent above or below the GRR, and differences are often only detectable at the third significant figure. During the period of main interest in this paper, 20-34 is the best fitting, and thus is used in all our calculations. On average, for the cohorts 1971 to 1986 , the $\operatorname{ORR}(20-34)$ is 1.1 per cent below the GRR, while the $\operatorname{ORR}(20-39)$ is 1.7 per cent above.

\section{Figure A1 Comparison of Gross Reproduction Rate with three definitions of Overall Replacement Ratio at age 0, England and Wales, 1971-2002}

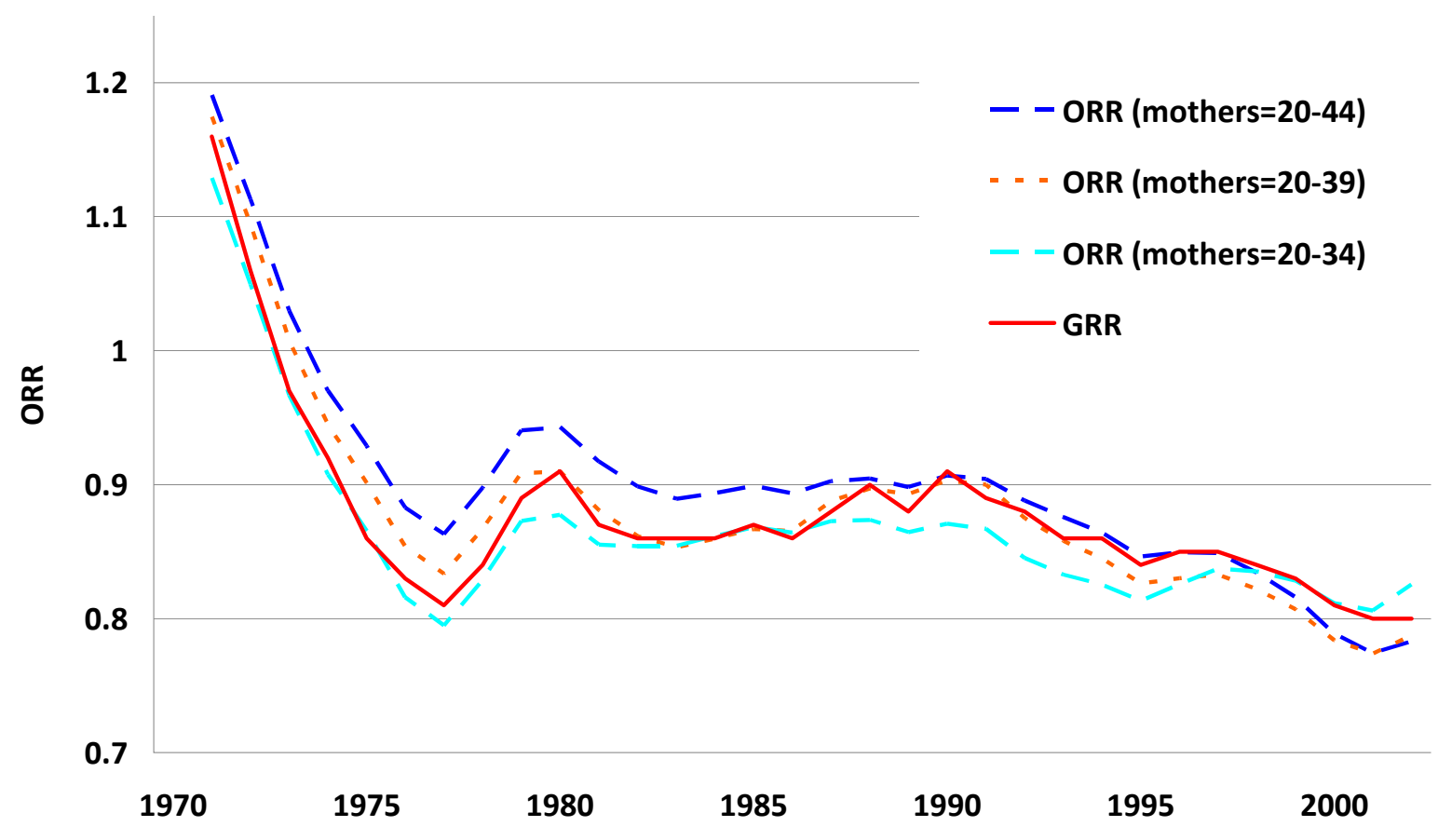




\section{Figure A2 Percentage deviation from Gross Reproduction Rate for three definitions of Overall Replacement Ratio, England \& Wales, 1971-2002}

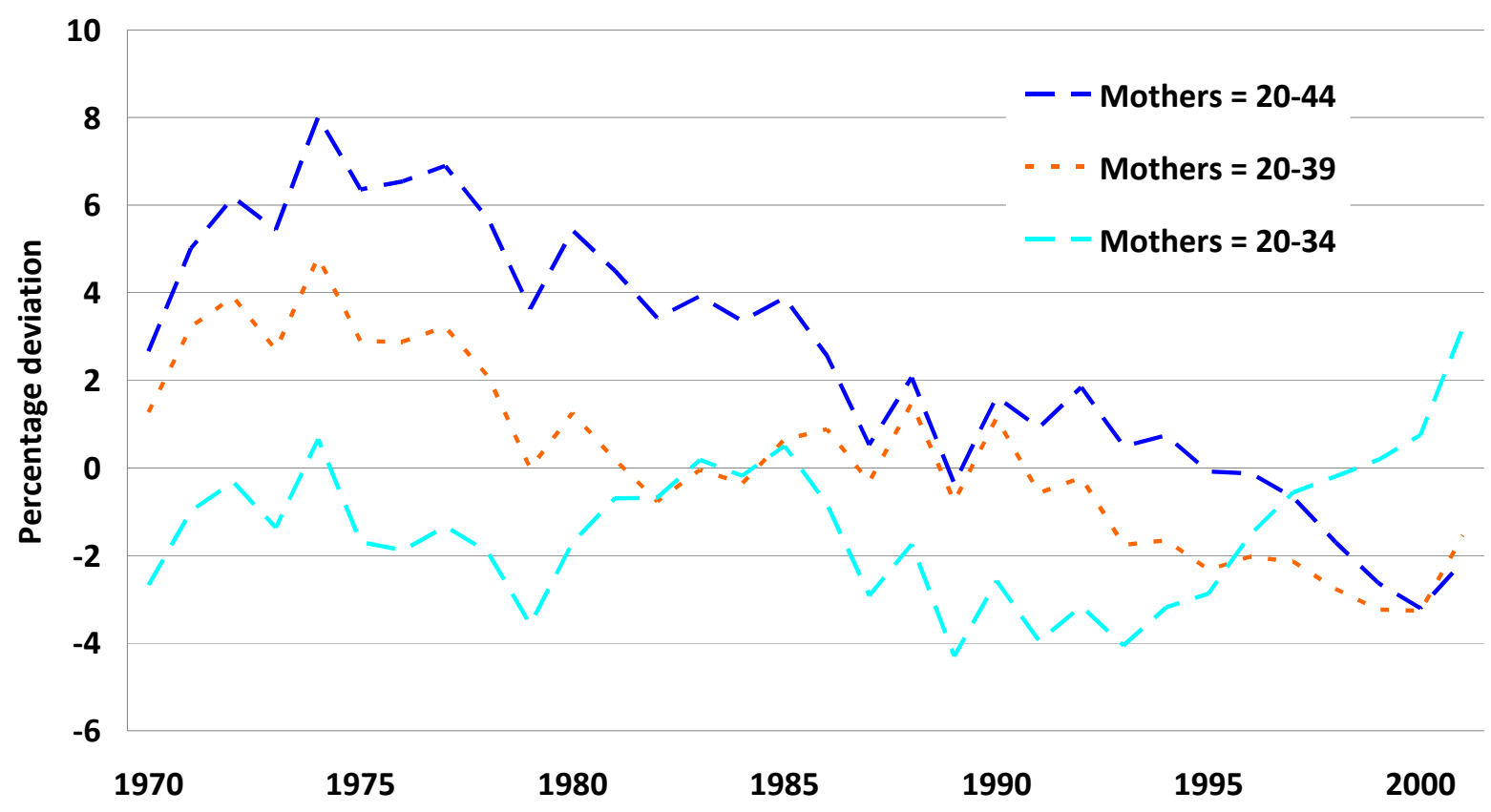

The pattern of change in the fit makes good sense when reflecting on what is known about the detailed age pattern of fertility. During the 1970 s and early-1980s fertility was relatively concentrated in the younger age-groups, thus 20-34 usually provides the best fit. However, with the increasing delay of fertility since the baby boom, a wider range gives a better fit. Our analysis of data from many European countries indicates that, although the exact dates for which each agerange is to be preferred vary from country to country, the overall pattern of change is broadly similar in much of Western Europe, and for the cohorts of most interest here 20-34 is the agerange of choice. 